\title{
Impact of global warming on cyclonic disturbances over south Asian region
}

\author{
Savita Patwardhan, Ashwini Kulkarni and K Krishna Kumar \\ Indian Institute of Tropical Meteorology, Pune, India. \\ Corresponding author.e-mail: patwar@tropmet.res.in
}

\begin{abstract}
A state-of-the-art regional climate modelling system, known as PRECIS (Providing REgional Climates for Impacts Studies) developed by the Hadley Centre for Climate Prediction and Research, UK is applied over the Indian domain to investigate the impact of global warming on the cyclonic disturbances such as depressions and storms. The PRECIS simulations at $50 \times 50 \mathrm{~km}$ horizontal resolution are made for two time slices, present (1961-1990) and the future (2071-2100), for two socioeconomic scenarios A2 and B2. The model simulations under the scenarios of increasing greenhouse gas concentrations and sulphate aerosols are analysed to study the likely changes in the frequency, intensity and the tracks of cyclonic disturbances forming over north Indian Ocean (Bay of Bengal and Arabian Sea) and the Indian landmass during monsoon season. The model overestimates the frequency of cyclonic disturbances over the Indian subcontinent in baseline simulations (1961-1990). The change is evaluated towards the end of present century (2071-2100) with respect to the baseline climate. The present study indicates that the storm tracks simulated by the model are southwards as compared to the observed tracks during the monsoon season, especially for the two main monsoon months, viz., July and August. The analysis suggests that the frequency of cyclonic disturbances forming over north Indian Ocean is likely to reduce by $9 \%$ towards the end of the present century in response to the global warming. However, the intensity of cyclonic disturbances is likely to increase by about $11 \%$ compared to the present.
\end{abstract}

\section{Introduction}

For a country like India, where the economy of the country mainly depends on agriculture, the performance of monsoon both in space and time is very crucial and important. Cyclonic disturbances (CD) such as storms and depressions originating from the two adjacent oceans of Indian landmass, viz., Arabian Sea and Bay of Bengal are recognized as the main synoptic weather systems over India during monsoon season. As the southwest monsoon progresses over India, the space-time variation of rainfall often occurs in association with the genesis and movement of these synoptic scale systems. Many studies indicate the decreasing trend in the observed frequency of monsoon season cyclonic disturbances in recent decades over Indian Ocean (Patwardhan and Bhalme 2001; Rajendra Kumar and Dash 2001; Singh 2001; Mandke and Bhide 2003). Niyas et al (2009) have studied the variability and long term trends in the frequency of cyclonic storms over north Indian Ocean. They have found the maximum decreasing trend in the frequencies of cyclonic storms during the monsoon season. They have also seen the increase in the intensities of the system. The influence of greenhouse gas-induced warming on tropical cyclone activity, over different ocean basins, has been investigated by many studies in recent years (Haarsma et al 1993; Bengtsson et al 1996; Walsh and Ryan

Keywords. Climate change; regional climate model; global warming; cyclonic disturbances; projections. 
2000; Sugi et al 2002). Analysis of the HadRM2 simulations shows a decrease in the frequency of cyclonic storms over Indian region in 2041-2060 due to global warming (Krishna Kumar et al 2005). Webster et al (2005) have shown that the number of tropical cyclones and tropical cyclone days have decreased in all ocean basins except the north Atlantic during the last 35 years, whereas the frequency of most intense cyclones is increasing. Murakami and Wang (2010) have studied the tropical cyclones in north Atlantic Ocean and found that the future changes of total tropical cyclone counts is statistically insignificant. However, the spatial pattern of the frequency of tropical cyclone occurrence will show marked change in future.

Most of the studies in recent period have indicated the significant decrease in the frequency of CDs over different ocean basins in the world. However, there are only few studies dealing exclusively with Indian subcontinent. Therefore, it will be interesting to investigate the likely impact of global warming on the cyclogenesis in the northern Indian Ocean, especially in the monsoon season, which is a prime rainy season in this part of the world.

\section{The Regional Climate Model (RCM) - PRECIS}

PRECIS is an atmospheric and land surface model of limited area and high resolution which can be configured for any part of the globe. Dynamical flow, the atmospheric sulphur cycle, clouds and precipitation, radiative processes, the land surface and the deep soil are all formulated in the model and boundary conditions are required to be specified at the limits of the model's domain. Information about every aspect can be diagnosed from the model. The basic aspects explicitly handled by the model are briefly outlined in Naguer et al (2002). For the present study, PRECIS has been configured for a domain extending from about $1.5^{\circ}-38^{\circ} \mathrm{N}$ and $56^{\circ}-103^{\circ} \mathrm{E}$ with a horizontal resolution of $0.44^{\circ}$ in latitude and $0.44^{\circ}$ in longitude.

Lateral boundary conditions, namely surface pressure, winds, temperature and humidity, provide the necessary dynamical atmospheric information at the latitudinal and longitudinal edges of the model domain. PRECIS is forced at its lateral boundaries by a Global Climate Model (GCM) of $150 \mathrm{~km}$ horizontal resolution called HadAM3H in so-called time slice experiments. HadAM3H is an atmosphere-only model which has been derived from the atmospheric component of HadCM3, the Hadley Centre's state-of-the-art coupled model which has a horizontal resolution of $3.75^{\circ}$ long. $\times 2.5^{\circ}$ lat. HadAM3H has been favoured over HadCM3 for driving the RCMs, since it has a higher resolution and exhibits an improved control climate, especially with respect to the positioning of the storm tracks of the Northern Hemisphere (Jones et al 1999). Thus, HadAM3H has been used to drive PRECIS for India over the two time slice periods.

Simulations using PRECIS have been performed to generate the climate for the present (1961-1990) and a future period (2071-2100) for two different SRES scenarios, both characterized by regionally focused development but with priority to economic issues in one (A2 scenario) and to environmental issues in the other (B2 scenario). The IPCC published a new set of scenarios in 2000 for use in the Third Assessment Report (Special Report on Emissions Scenarios - SRES). The SRES scenarios were constructed to explore future developments in the global environment with special reference to the production of greenhouse gases and aerosol precursor emissions. The detailed description of SRES scenarios are reported in Nakicenovic et al (2000).

The high-resolution regional simulations generated using PRECIS have been studied in detail to evaluate the model skill in representing the regional climatological features, especially the summer monsoon characteristics. The RCMs have shown reasonable skill in depicting the surface climate over the Indian region. Rainfall maximum over the west coast of India and the rain-shadow region in the southeastern peninsula is well simulated by the model (Rupa Kumar et al 2006). The seasonal precipitation patterns in the baseline simulation are quite similar to those observed, indicating that the baseline simulations provide an adequate representation of present-day conditions. However, there exists some quantitative biases in the spatial patterns. A conspicuous bias is considerably higher than the observed monsoon precipitation over east central India in the baseline simulation.

\section{Methodology}

The CDs are identified using the PRECIS derived parameters, viz., daily surface winds and daily mean sea level pressure. The criteria used for the identification of the system are as follows:

- The centre of CD is a grid point at which the sea level pressure over the region of cyclogenesis is minimum.

- The centre of CD is a grid point at which the sea level pressure departure from the daily mean should be less than $-5 \mathrm{hPa}$.

- Maximum wind speed at $10 \mathrm{~m}$ level near the centre of the disturbance should be more than 17 knots.

- The system should persist for at least two days. 
28 Jun 1979

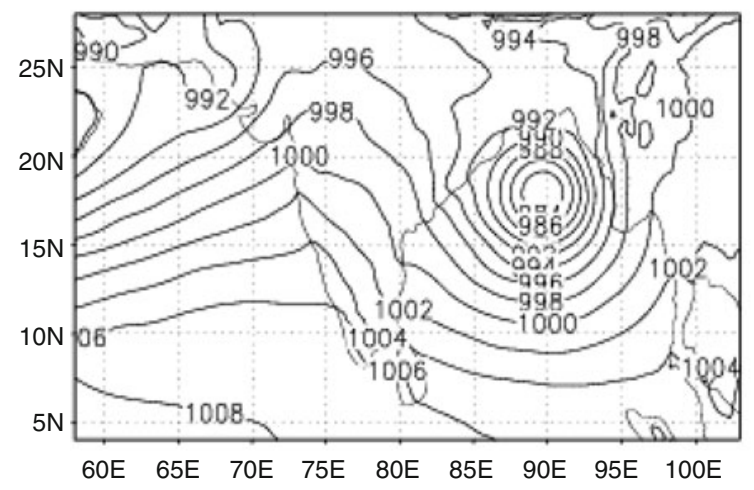

30 Jun 1979

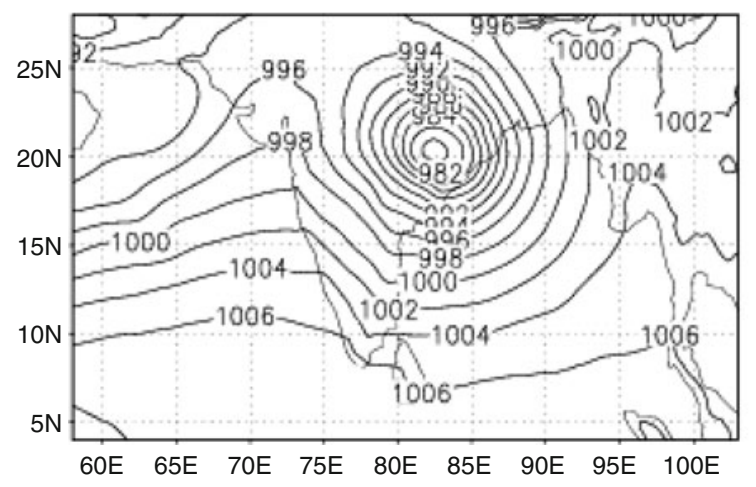

29 Jun 1979
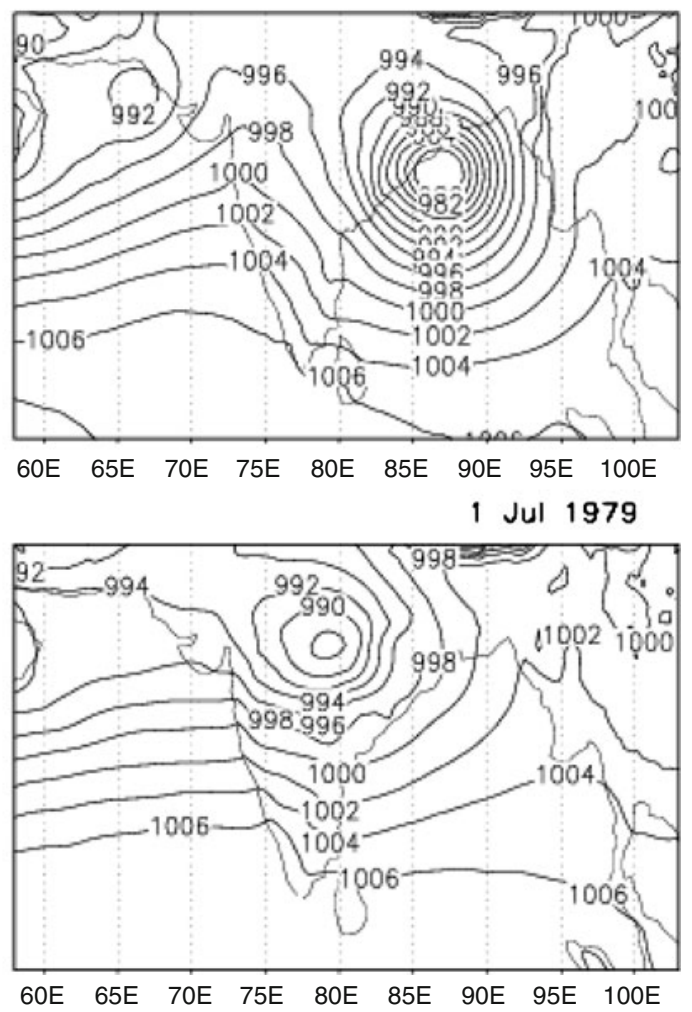

Figure 1. Mean sea level pressure pattern of the PRECIS simulated cyclonic storm.

Table 1. Monthly frequencies of cyclonic disturbances (per year) formed over north Indian Ocean and Indian landmass as simulated by PRECIS. The values in the parenthesis indicate the mean maximum intensity (knots).

\begin{tabular}{lcccrr}
\hline & June & July & August & September & Monsoon \\
\hline Observed & $1.5(27)$ & $1.4(23)$ & $2.1(24)$ & $2(29)$ & $7(26)$ \\
Baseline & $1.6(34)$ & $2.2(32)$ & $1.7(29)$ & $2.7(31)$ & $8.2(31)$ \\
A2 scenario & $1.7(37)$ & $1.7(34)$ & $1.4(30)$ & $2.6(34)$ & $7.4(34)$ \\
\hline
\end{tabular}

The storms are identified for baseline as well as A2 scenario, using the above criteria. Figure 1 gives the model simulated mean sea level pressure pattern associated with typical cyclonic storm simulated by PRECIS in baseline simulation. The system forms over Bay of Bengal region (near $89.9^{\circ} \mathrm{E}, 17.4^{\circ} \mathrm{N}$ location). Next day, it intensifies while moving in the northwesterly direction into the Indian landmass. During its movement, it further intensifies on the third day and subsequently weakens on the fourth day, as seen from figure 1. The CDs are also simulated well in A2 scenario (figure not shown). The model captures the cyclogenesis in the north Indian Ocean quite realistically due to its high horizontal resolution. Bengtsson et al (2007) have also expressed the need to increase the resolution in climate modelling studies to capture the correct structure of tropical cyclone upto at least $50 \mathrm{~km}$ or equivalent. The storms thus identified are analyzed to see the likely changes in their frequency, intensity and the tracks under the influence of increased GHG concentrations.

The results obtained for A2 and B2 scenarios are quite similar, though they differ slightly in magnitude. Hence in the present study the climate change impacts are assessed and presented with respect to $\mathrm{A} 2$ scenario only.

\section{Discussion}

The frequency and the intensity of the cyclonic disturbances forming over north Indian Ocean and the Indian landmass during individual monsoon months and the season as a whole are shown in table 1. It can be seen from the table that the model overestimates the frequency of disturbances, viz., 8.2 disturbances per season as compared to the observed frequency of 7 disturbances per season. There is no significant change under A2 scenario 
though slight decrease in the frequency (7.4 disturbances per season) is seen towards the end of 21st century, i.e., towards 2080s due to the increase in GHG concentrations. This change is within the limits of natural variability (the frequency of cyclonic disturbances in baseline has mean 8 and standard deviation 2.1). The decrease in monsoon CDs is mainly due to reduction in July and August systems as can be seen from table 1. The intensity of the synoptic system is the maximum intensity of the wind associated with the system. The values in parenthesis in the table are the mean maximum winds (expressed in knots) associated with the system. The model has positive bias in the intensity of cyclonic disturbances in the baseline simulations (31 knots) as compared to the observed intensity of 26 knots for season as a whole. The positive bias in the intensity of CDs is seen in all the four monsoon months. The model indicates intense CDs in the future in monsoon months, with $11 \%$ increase in the intensity towards the end of present century as compared to baseline. Oouchi et al
(2006) have studied the possible changes in tropical cyclones using high resolution, global atmospheric model. They have indicated the reduction of tropical cyclones in north Indian Ocean in future with the possibility of higher risks of more devastating systems.

The CDs simulated by the model are analysed to investigate the possible changes in the frequency and intensity of depressions and the cyclonic storms separately. The analysis shows that the frequency of depressions (cyclonic storms) may decrease (increase) by $28 \%(34 \%)$ in the period 2071-2100 as compared to that in 1961-1990. Also the average intensity of the depressions (cyclonic storms) may increase by $2.4 \%(3.8 \%)$ in future indicating the more intense CDs in future.

The CDs forming over warm regions of Bay of Bengal follow northwesterly track along the monsoon trough region to give ample rainfall on the way. The storm tracks are therefore analysed to see the possible changes in their pattern. Figure 2 gives the tracks of the CDs simulated by PRECIS
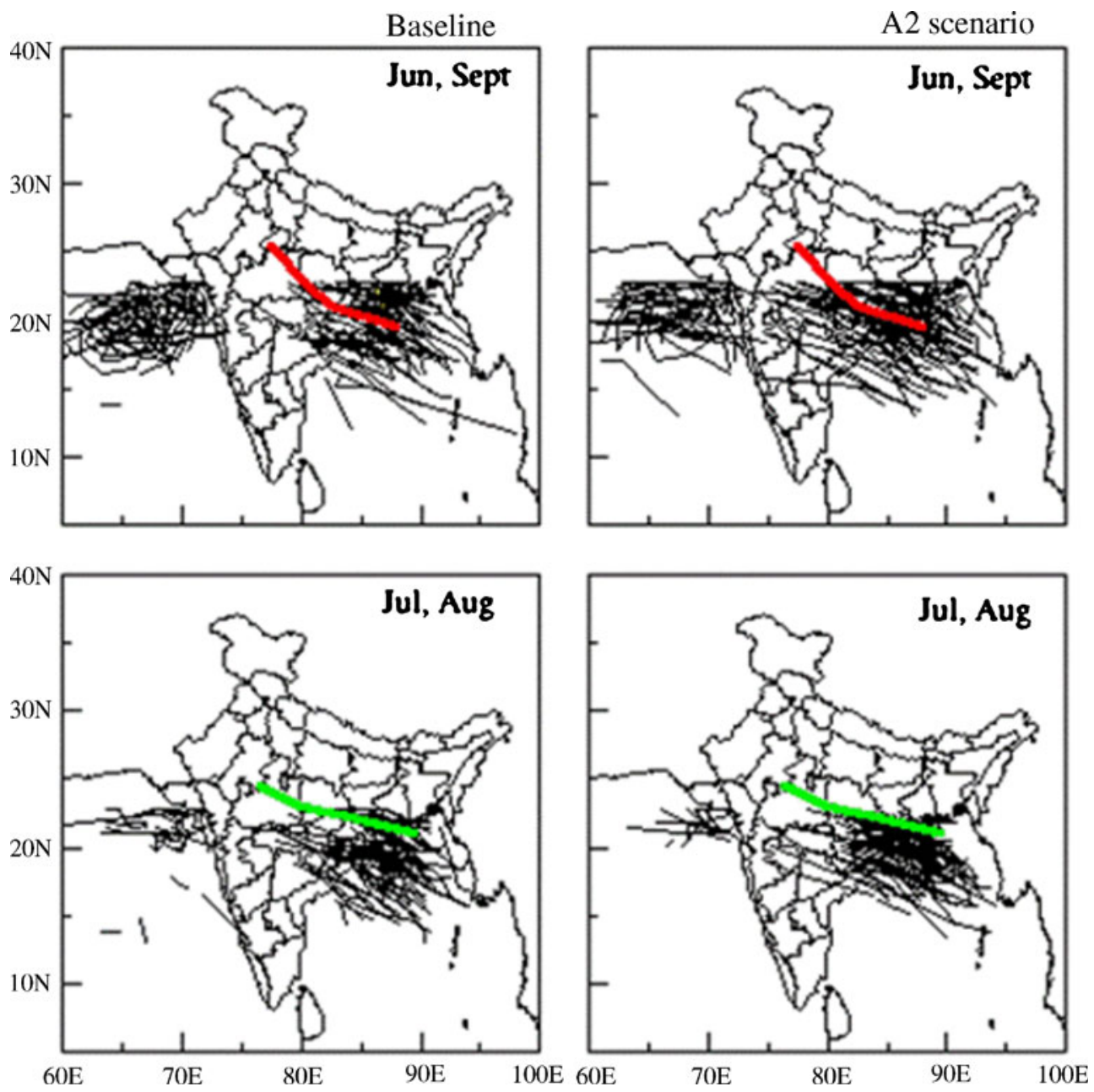

Figure 2. Storm tracks simulated by PRECIS for baseline (1961-1990) and towards the end of present century (2071-2100). The normal tracks in July and August (green) and June and September (red) are also shown. 

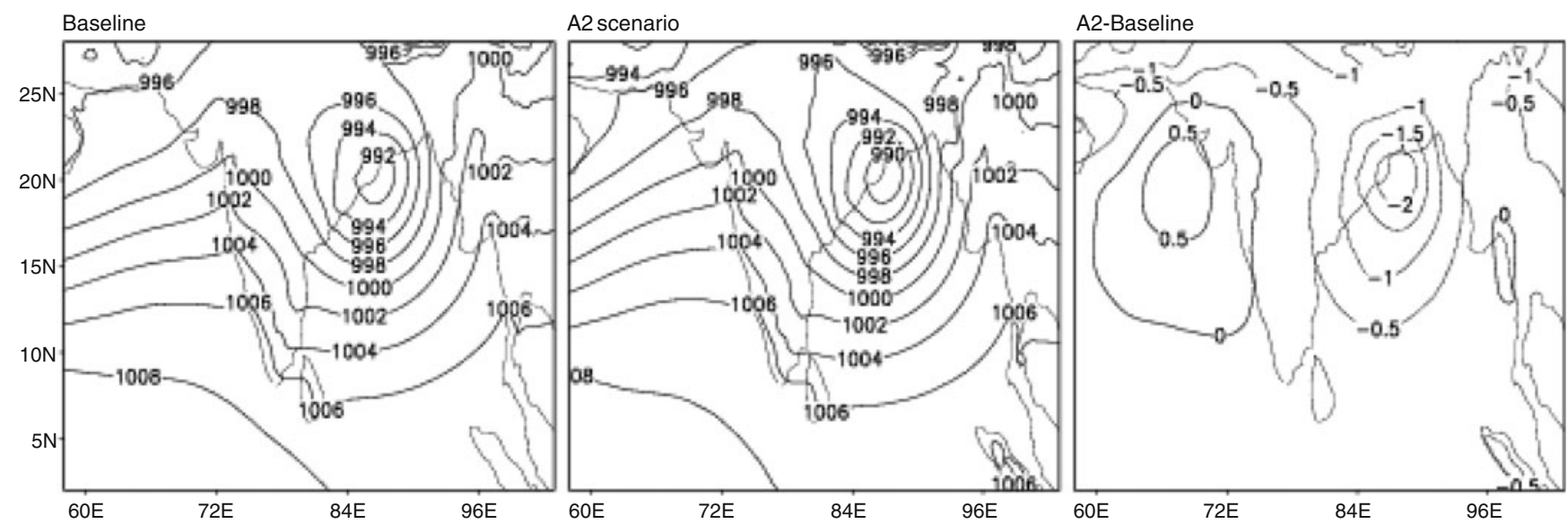

Figure 3. Composite of mean sea level pressure (hPa) attained at the maximum intensity of the cyclonic disturbances for baseline (left), A2 scenario (middle) and the difference between minimum pressure attained (right).
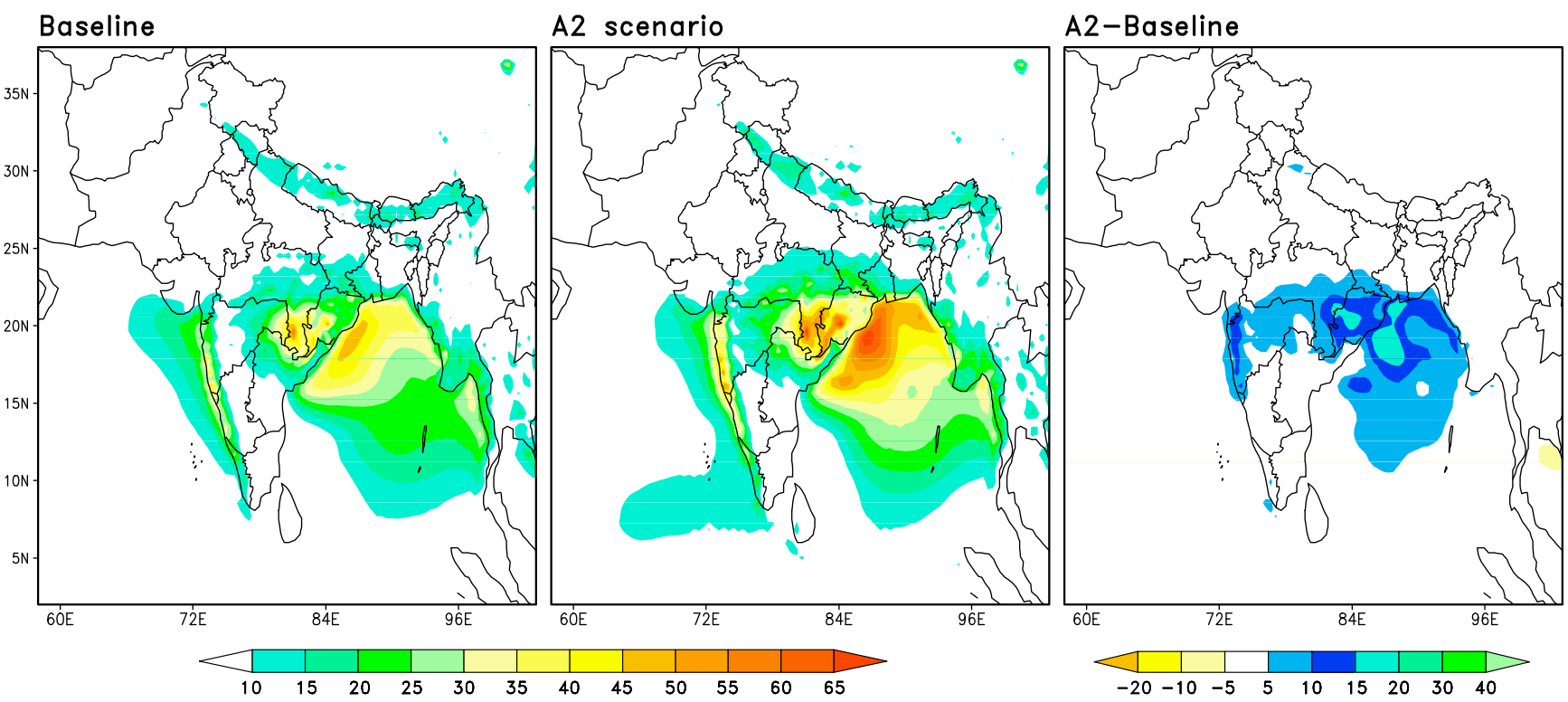

Figure 4. Composite rainfall $(\mathrm{mm})$ received during the disturbances for baseline (left), A2 scenario (middle) and the difference between the composite rainfall (right).

in baseline (left) and A2 scenario (right) along with their normal observed tracks for monsoon months. Upper panels show the CDs forming in the month of June and September along with the normal track for these months. The CDs forming in the Bay of Bengal have short tracks, in the baseline simulations, as compared to the tracks for A2 scenarios (upper panels). The systems in baseline simulations do not reach west central India, to the west of $80^{\circ} \mathrm{E}$ as they do in $\mathrm{A} 2$ scenario (upper right panel). The northerly track after passing $80^{\circ} \mathrm{E}$ as seen from normal tracks is missing in PRECIS simulations. The CDs forming in the month of July and August are to the south of normal tracks in baseline as well as A2 scenario (lower panels, figure 2). Model simulated CDs in the month of July and August do not cross $80^{\circ} \mathrm{E}$ in both the simulations.
The composite analysis of mean sea level pressure (MSLP) and rainfall also hints the increase in the intensity of CD. Figure 3 gives the composite of the MSLP that was attained at the maximum intensity of the system. The minimum central pressure for the baseline is $990 \mathrm{hPa}$ (left panel), whereas it further reduces to $988 \mathrm{hPa}$ in the future (middle panel) indicating the intensification of the system under warmer climate. The central pressure associated with the system drops by around $2.5 \mathrm{hPa}$ in warming scenario as shown in figure 3 (right panel). Pisharoty and Asnani (1957) have shown that the heaviest precipitation occurs in the southwest sector of the depression. The model is able to capture this rainfall maximum associated with the CD. The increased rainfall along the monsoon trough region during the passage of $\mathrm{CD}$ 
is well captured in baseline simulations (figure 4, left panel). The rainfall composites during the CD forming over the Bay of Bengal region also suggests that the rainfall associated with the $\mathrm{CD}$ is likely to be more in future (2071-2100) compared to the baseline (1961-1990) due to the intensification of the systems (figure 4). Right panel of figure 4 gives the difference of rainfall composite, which indicates the rise in rainfall in warming scenario. The rise in rainfall may be maximum near Orissa coast $(>15 \mathrm{~mm})$ and over the state of Orissa and may decrease towards central India $(5-10 \mathrm{~mm})$. Knutson et al $(2008,2010)$ have also indicated increase in the near storm rainfall rate in future in response to global warming.
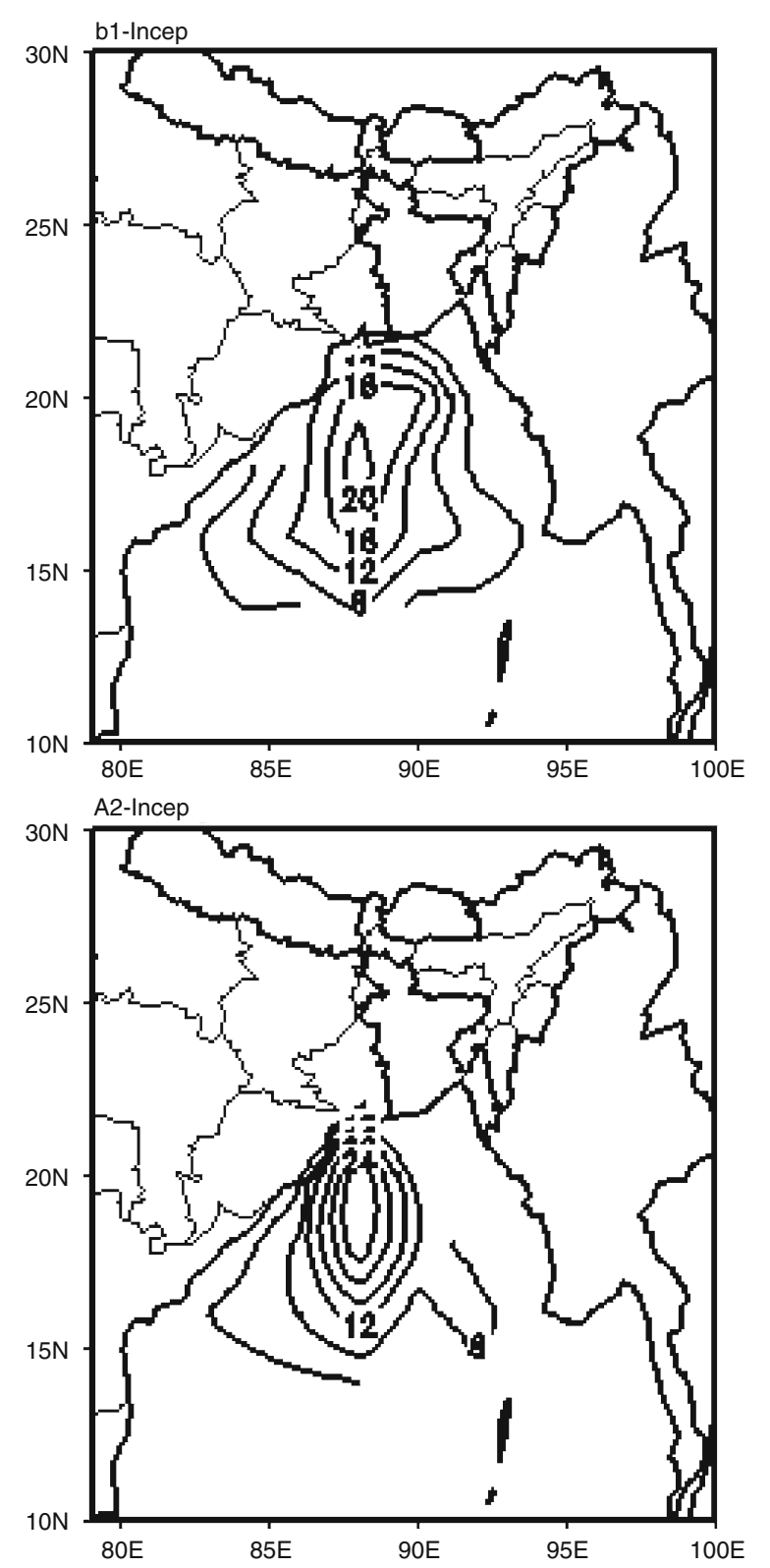

The location of inception of CD is analysed for the Bay of Bengal region to assess the impact of global warming on the inception of CD. Figure 5 gives the location of inception (left panel) for baseline (upper left) and for A2 scenario (lower left). The maximum frequency of inception can be around $18^{\circ} \mathrm{N}$ for baseline and it is likely to be shifted northwards slightly, i.e., towards $19^{\circ} \mathrm{N}$ by the end of the present century. The formation of $\mathrm{CD}$ may be concentrated close to $88^{\circ} \mathrm{E}$ in future with respect to baseline. The favourable inception location may shift westwards near Orissa coast in 2080 s as compared to 1970 s. The model does not show much change in the landfall position in warming scenario towards the end of the present century,
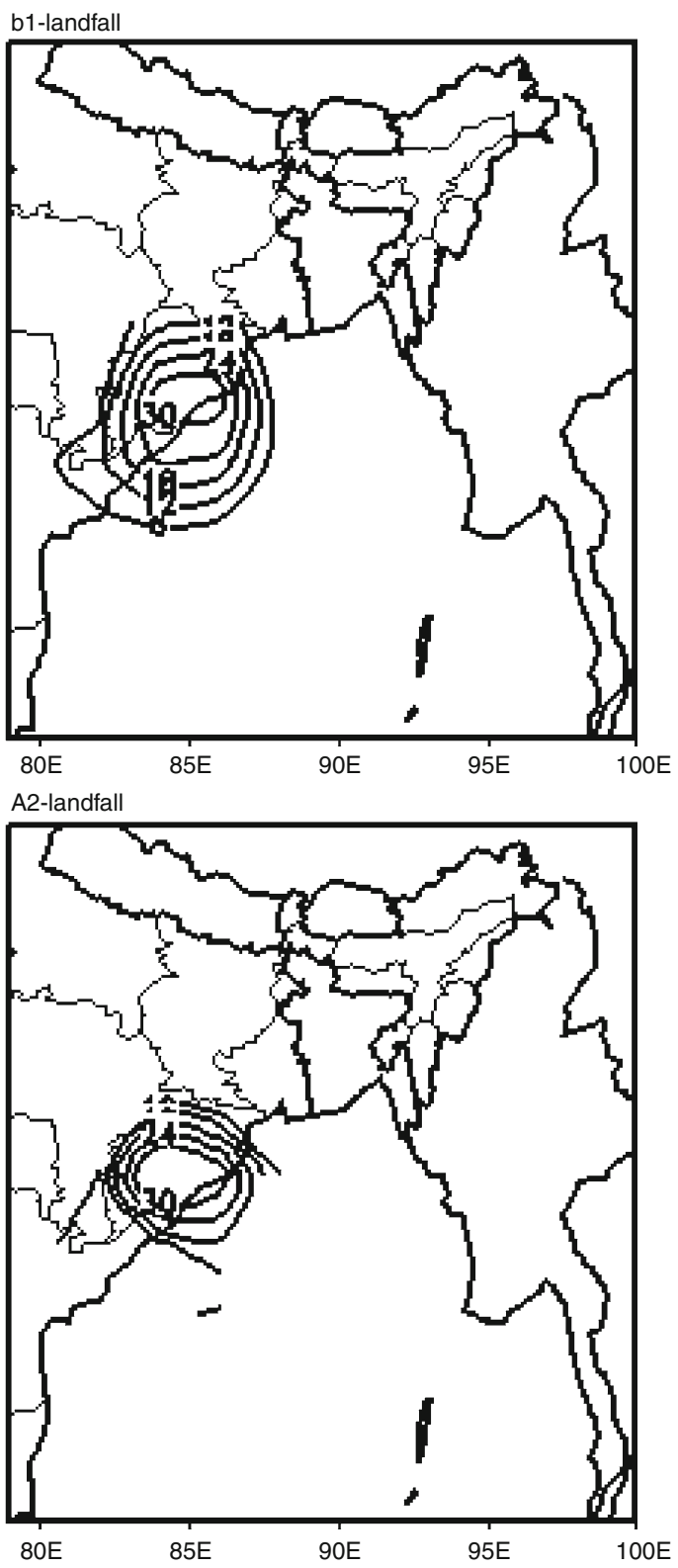

Figure 5. Inception (left panel) and the landfall (right panel) of cyclonic disturbances simulated by PRECIS for baseline (upper panel) and for warming scenario (lower panel). 

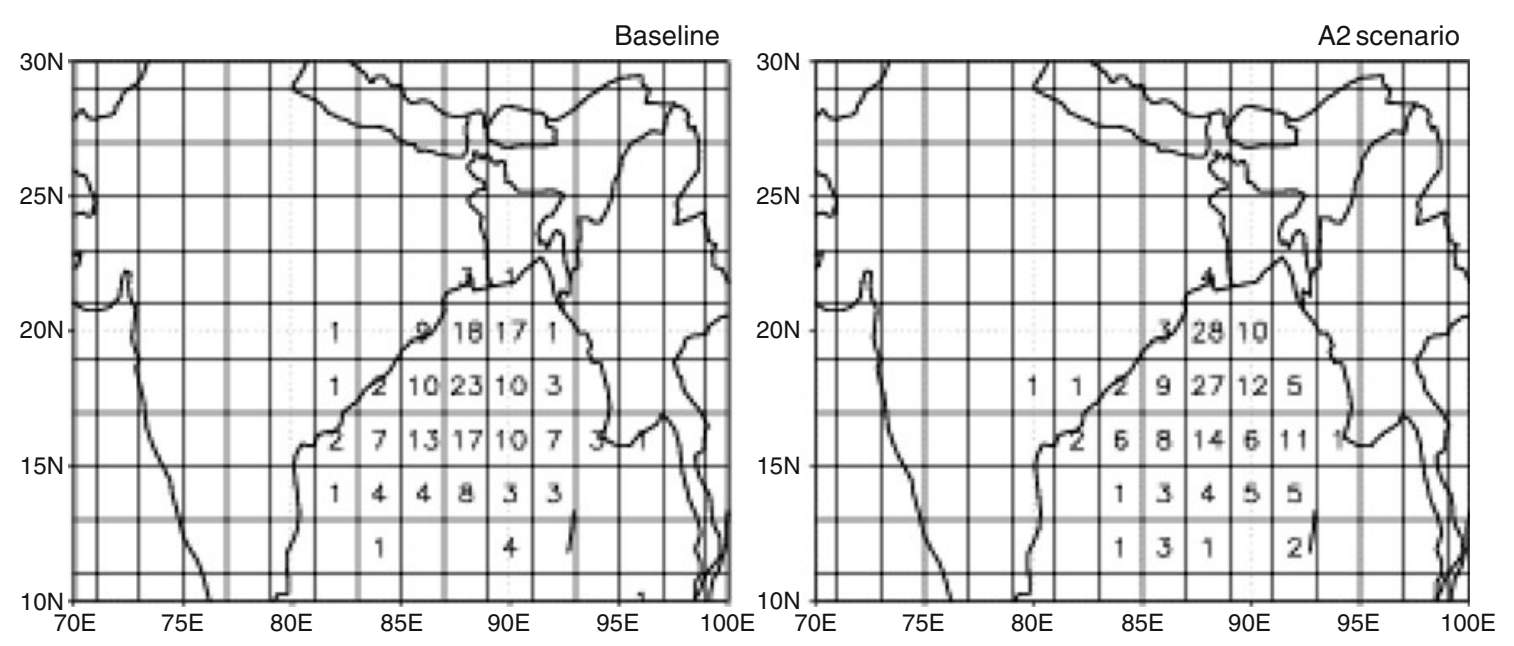

Figure 6. Frequency of monsoon disturbances forming over Bay of Bengal for baseline (left) and for A2 scenario (right).

as seen from figure 5. Even though the CD and CD days are seen to be less in warming scenario, no change is seen in the duration of the CDs in future when compared with model baseline simulations.

The spatial pattern of frequency of CD occurring over Bay of Bengal is analysed to assess the likely changes in spatial distribution of frequency. It can be seen from figure 6 that the frequencies of $\mathrm{CD}$ are likely to reduce over southwest Bay of Begal (23\%) and northeast Bay of Bengal (15\%), whereas $12 \%$ increase in the frequency may be seen over northwestern Bay of Bengal. There may not be significant changes over southeastern sector of Bay of Bengal where comparatively less number of CDs are formed. This change in the spatial pattern of frequency is also projected over north Atlantic Ocean by Murakami and Wang (2010).

\section{Summary}

Climate change is now universally recognized as a significant global environmental challenge. It is now well established that the warming climate will definitely have an impact on the monsoonal climate over India. Cyclonic disturbances play a major role in the performance and quantum of mean seasonal rainfall. In this view, the impact of global warming on the cyclogenesis over north Indian Ocean and the Indian landmass, is assessed using high resolution regional climate model - PRECIS. The model simulations are evaluated to study the impact on frequency, intensity and tracks of the cyclonic disturbances. PRECIS, with its high horizontal resolution, is able to capture the synoptic systems realistically. Though the analysis indicates slight decrease in the number of CDs, there may not be significant change in the frequency of systems forming over Indian subcontinent during monsoon season. The analysis also indicates the possibility of intense systems in future under the effect of increased GHG concentrations. The composite analysis of rainfall as well as mean sea level pressure also confirm the increase in the intensity of these disturbances in future. Though the tracks in model simulations are towards the southern latitude as compared to the normal observed tracks, there is no significant change in the tracks, towards the end of present century as compared to the model baseline simulations. As this is a preliminary study based on one single simulation of the regional climate model, the results may be used only qualitatively, with caution. More simulations are required to reduce the uncertainty in the results. Further study is required to assess the different factors responsible for the changes in the cyclogenesis.

\section{Acknowledgements}

This work is part of a Joint Indo-UK collaborative programme on climate change impacts in India. The authors are grateful to the Department for Environment, Food and Rural Affairs (DEFRA), Government of United Kingdom, for sponsoring this project and the Ministry of Environment and Forest (MoEF), Government of India, for co-ordinating its implementation. The project team is grateful to the Hadley Centre for Climate Prediction and Research, UK Meteorological Office, for making the regional models and their data products available for this study. The authors are thankful to Director, IITM, Pune for his keen interest and support and the anonymous reviewers for their suggestions that helped a lot in improving the manuscript. 


\section{References}

Bengtsson L, Botzet M and Esch M 1996 Will greenhouse gas-induced warming over the next 50 years lead to higher frequency and greater intensity of hurricanes?; Tellus 48A $57-73$.

Bengtsson L, Hodges K L, Esch M, Keenlyside N, Kornblueh L, Luo J J and Yamagata T 2007 How many tropical cyclones change in a warmer climate?; Tellus 59A 539-561.

Haarsma R J, Mitchell J F B and Senior C A 1993 Tropical disturbances in a GCM; Clim. Dyn. 8 247-257.

Jones R G et al 1999 Configuring new climate models for Europe with improved climatologies via better representation of physical processes; UKMO 2nd year report for MERCURE. EC contract ENV4.CT97.0485.

Knutson T R, Sirutis J J, Garner S T, Vecchi G A and Held I M 2008 Simulated reduction in Atlantic hurricane frequency under twenty-first-century warming conditions; Nature Geosci. 1 359-364.

Knutson $\mathrm{T}$ R, McBride J L, Chan J, Emanuel K, Holland G, Landsea C, Held I, Kossin J P, Srivastava A K and Sugi M 2010 Tropical cyclones and climate change; Nature Geosci. 3 157-163.

Krishna Kumar K, Mishra P K, Patwardhan S K, Revadekar J V and Rupa Kumar K 2005 Impact of global warming on the cyclonic storms in the Bay of Bengal and the Arabian Sea; In: Predicting Meteorological Events: Mathematical Approach (ed.) Mahanti N C, pp. 114-125.

Mandke S K and Bhide U V 2003 A decreasing storm frequency over Bay of Bengal; J. Ind. Geophys. Union 7(2) $53-58$.

Murakami H and Wang B 2010 Future change of north Atlantic tropical cyclone tracks projection by a $20-\mathrm{km}-$ mesh global atmospheric model; J. Climate 23 2699-2721.

Naguer M, Jones R, Hessel D, Hudson D, Wilson S, Jenkins J and Mitchell J 2002 Workbook on generating high resolution climate change scenarios using PRECIS; Hadley Centre for Climate Prediction and Research, Met Office, Bracknell, UK, 43pp.
Nakicenovic N A et al 2000 Special Report on Emission Scenarios; A special report of working Group III of the International Panel on Climate Change, (Cambridge, UK: Cambridge University Press) 599p.

Niyas N T, Srivastava A K and Hatwar H R 2009 Variability and trend in the cyclonic storms over north Indian Ocean; Met. Monograph 3 35p.

Oouchi K, Yoshimura J, Yoshimura H, Mizuta S and Noda A 2006 Tropical cyclone climatology in a global-warming climate as simulated in a $20 \mathrm{~km}$-mesh global atmospheric model: Frequency and wind intensity analyses; J. Met. Soc. Japan 84(2) 259-276.

Patwardhan S K and Bhalme H N 2001 A study of cyclonic disturbances over India and the adjacent Ocean; Int. J. Climatol. 21 527-534.

Pisharoty P R and Asnani G C 1957 Rainfall around monsoon depressions over India; Ind. J. Meteor. Geophys. 8 15-20.

Rajendra Kumar J and Dash S K 2001 Interdecadal variations of characteristics of monsoon disturbances and their epochal relationships with rainfall and other tropical features; Int. J. Climatol. 21(6) 759-771.

Rupa Kumar K, Sahai A K, Krishna Kumar K, Patwardhan S K, Mishra P K, Revadekar J, Kamala K and Pant G B 2006 High-resolution climate change scenarios for India; Curr. Sci. 90(3) 334-345.

Singh O P 2001 Long term trends in the frequency of monsoonal cyclonic disturbances over north Indian Ocean; Mausam 52(4) 655-658.

Sugi M, Noda A and Sato N 2002 Influence of the global warming on tropical cyclone climatology: An experiment with the JMA global model; J. Met. Soc. Japan 80(2) 249-272.

Walsh K and Ryan B F 2000 Tropical cyclonic intensity increase near Australia as a result of climate change; J. Climate 13 3029-3036.

Webster et al 2005 Changes in tropical cyclone number, duration and intensity in a warming environment; Science 309 1844-1846. 